\title{
Prevalence and correlates of pain in the Canadian National Palliative Care Survey
}

\author{
Keith G Wilson PhD ${ }^{1}$, Harvey Max Chochinov MD PhD², Pierre Allard MD PhD ${ }^{3}$, Srini Chary $\mathrm{MD}^{4}$, Pierre R Gagnon $\mathrm{MD}^{5}$, \\ Karen Macmillan $\mathrm{BScN}^{6}$, Marina De Luca $\mathrm{MD}^{7}$, Fiona $\mathrm{O}^{\prime}$ Shea $\mathrm{MB}^{8}$, David Kuhl MD PhD ${ }^{9}$, Robin L Fainsinger $\mathrm{MD}^{10}$
}

\begin{abstract}
KG Wilson, HM Chochinov, P Allard, et al. Prevalence and correlates of pain in the Canadian National Palliative Care Survey. Pain Res Manage 2009;14(5):365-370.
\end{abstract}

BACKGROUND: Pain is a common problem for people with cancer who are nearing the ends of their lives.

OBJECTIVE: In the present multicentre Canadian study of palliative cancer care, the prevalence of pain, its perceived severity and its correlates across a range of physical, social, psychological, and existential symptoms and concerns were examined.

METHODS: Semistructured interviews were conducted with 381 patients. In addition to inquiring about pain, the interview also assessed 21 other symptoms and concerns, and collected information about demographic characteristics, functional status and medication use.

RESULTS: Pain of any intensity was reported by 268 (70.3\%) participants, although for 139 (36.5\%), the severity was rated as minimal or mild. For $129(33.9 \%)$ individuals, pain was reported as moderate to extreme, and considered by the respondents to be an important ongoing problem. Patients who reported moderate to extreme pain were younger than other participants, but had lower functional status and a shorter median survival duration. They were more likely than other participants to be treated with opioid medications $(\mathrm{P}<0.001)$ and, less reliably, with benzodiazepines $(\mathrm{P}=0.079)$. Compared with participants with no, minimal or mild pain, those with moderate to extreme pain had a higher prevalence of distressing problems on 11 of 21 other symptoms and concerns. The strongest correlations were with general malaise $(\mathrm{rho}=0.44)$, suffering $(\mathrm{rho}=0.40)$, nausea $($ rho $=0.34)$, weakness $($ rho $=0.31)$, drowsiness $($ rho $=0.29)$ and anxiety $($ rho $=0.29)$.

CONCLUSIONS: Pain continues to be a difficult problem for many patients who are receiving palliative cancer care, particularly younger individuals who are nearing death.

Key Words: Cancer pain; Palliative care; Prevalence

$\mathrm{M}$ any patients with advanced cancer are concerned about dying in pain (1), and pain management receives very high priority ratings when patients are initially referred to palliative care (2). Indeed, pain continues to be a prevalent symptom among the terminally ill. Two recent systematic reviews have concluded that among patients with advanced cancer, the overall prevalence of pain ranges from $62 \%$ to $86 \%$, with a pooled prevalence of $71 \%(3,4)$. Although not all patients suffer from high-intensity pain, one review of 22 studies of individuals with advanced cancer concluded that approximately $45 \%$ had pain that could be characterized as moderate to severe

\section{La prévalence et les corrélats de la douleur dans le cadre de l'enquête nationale sur les soins palliatifs}

HISTORIQUE : La douleur est un trouble courant chez les personnes
cancéreuses en fin de vie.
OBJECTIF : Dans la présente étude canadienne multicentre sur les soins
palliatifs du cancer, on s'est penché sur la prévalence de la douleur, sa
gravité perçue et ses corrélats à l'égard d'une série de craintes et symptômes
physiques, sociaux, psychologiques et existentiels.
MÉTHODOLOGIE : On a effectué des entrevues semi-structurées
auprès de 381 patients. En plus d'aborder la douleur, l'entrevue a
également permis d'évaluer 21 autres craintes et symptômes et de colliger
de l'information sur les caractéristiques démographiques, les capacités
fonctionnelles et l'utilisation de médicaments. RÉSULTATS : Deux cent soixante-huit (70,3, \%) participants ont déclaré une douleur d'intensité variable, dont 139 (36,5\%) une douleur minimale ou bénigne. Par contre, 129 (33,9\%) répondants déclaraient une douleur modérée à extrême, qu'ils considéraient comme un problème continu important. Ces patients étaient plus jeunes que les autres, mais avaient des capacités fonctionnelles plus basses et une moins longue durée de survie. Ils étaient plus susceptibles que les autres participants de recevoir un traitement aux opiacés $(\mathrm{P}<0,001)$ et, de manière moins fiable, aux benzodiazépines $(\mathrm{P}=0,079)$. Par rapport aux participants qui ne ressentaient aucune douleur ou souffraient de douleurs minimales ou bénignes, ceux qui ressentaient des douleurs modérées à extrêmes affichaient une prévalence plus élevée de troubles pénibles à l'égard de 11 des 21 autres craintes et symptômes. Les corrélations les plus marquées portaient sur le malaise généralisé $(\mathrm{rho}=0,44)$, la souffrance $(\mathrm{rho}=0,40)$, les nausées $(\mathrm{rho}=0,34)$, la faiblesse $(\mathrm{rho}=0,31)$, la somnolence $(\mathrm{rho}=0,29)$ et l'anxiété $(\mathrm{rho}=0,29)$.

CONCLUSIONS : La douleur continue d'être un problème difficile pour de nombreux patients qui reçoivent des soins palliatifs du cancer, notamment les personnes plus jeunes peu avant leur mort.

(4), although various individual studies have reported a range of values from $20 \%$ to $65 \%$ (5). Some of the difficulties in interpreting the literature on pain in advanced cancer are that studies have used a range of methodologies (eg, chart reviews, interviews, proxy reports) and assessment measures, often with small samples, which make direct comparisons difficult (4).

Fortunately, most cancer pain can be controlled with implementation of the World Health Organization analgesic guidelines (6) or prompt introduction of strong opioids (7). Evaluation of these interventions suggests that over $70 \%$ of patients can obtain good relief, and almost $90 \%$ can achieve

${ }^{1}$ Department of Psychology, The Ottawa Hospital Rehabilitation Centre, Ottawa, Ontario; ${ }^{2}$ Department of Psychiatry, University of Manitoba, and The Manitoba Palliative Care Research Unit, CancerCare Manitoba, Winnipeg, Manitoba; ${ }^{3}$ Department of Medicine, University of Ottawa, Ottawa, Ontario; ${ }^{4}$ Division of Palliative Medicine, Department of Oncology, University of Calgary, Calgary, Alberta; ${ }^{5}$ Faculty of Pharmacy, Université Laval, Québec, Québec; ${ }^{6}$ Grey Nuns Community Hospital, Edmonton, Alberta; ${ }^{7}$ BC Cancer Agency - Centre for the Southern Interior, Kelowna, British Columbia; ${ }^{8}$ Dr H Bliss Murphy Cancer Centre, St John's, Newfoundland and Labrador; ${ }^{9}$ Department of Family and Community Medicine, University of British Columbia, Vancouver, British Columbia; ${ }^{10}$ Division of Palliative Care Medicine,

Department of Oncology, University of Alberta, Edmonton, Alberta

Correspondence: Dr Keith G Wilson, Department of Psychology, The Ottawa Hospital Rehabilitation Centre, 505 Smyth Road, Ottawa, Ontario K1H 8M2. Telephone 613-737-8899 ext 75608, fax 613-737-7056, e-mail kewilson@ottawahospital.on.ca 
pain control that is at least satisfactory (8-10). The provision of adequate pain relief has substantial implications for other aspects of quality of life, such as increased activity, improved mood and a reduction in the severity of other symptoms (8). Conversely, however, it would appear that perhaps $10 \%$ to $30 \%$ of individuals who are terminally ill with cancer continue to tolerate pain that causes significant discomfort and disability. In the present study, we attempted to identify, among a large cohort of patients receiving palliative care, the prevalence of those individuals who report that pain is a significant ongoing problem. We then examined the demographic and clinical characteristics of this group, and the physical, psychological, social and existential problems that are associated with pain.

\section{METHODS}

\section{Participants}

The data for the present project were collected as part of the Canadian National Palliative Care Survey (NPCS). The recruitment procedures and general protocol of the NPCS have been reported in previous publications $(1,11,12)$. The NPCS was a multicentre study of quality of life concerns among people who had been referred for palliative care consultations or admitted to palliative care units. There were eight recruiting centres across Canada, representing Newfoundland and Labrador, Quebec, Ontario, Manitoba, Saskatchewan, Alberta and British Columbia.

Potential participants were informed about the study by palliative care clinicians involved in their treatment. In general, this discussion took place after the clinician had developed some knowledge of the patient's problems and circumstances, and developed a sufficient working alliance so that the topic of research participation would not intrude on clinical care. All NPCS participants had foreshortened life expectancies because of cancer, with clinicians estimating that the patients were likely to die within six months. The participants had been informed of their prognosis, were cognitively and physically well enough to tolerate an interview, and were not in an acute medical or psychosocial crisis. Interviews were conducted in either English or French. The NPCS protocol was approved by research ethics boards from all participating institutions, and respondents completed a written acknowledgment of informed consent. A total of 381 individuals provided information about the presence and perceived severity of pain.

\section{Interview protocol}

Data collection for the NPCS involved the administration of semistructured interviews, conducted in person by trained interviewers. The interviewers also had previous clinical experience in nursing, social work or psychology, or extensive research experience in palliative care. The interview guide included questions about demographic and social circumstances. Embedded in the guide was a 22-item version of the Structured Interview of Symptoms and Concerns (SISC; 13). The SISC uses a format of single-item screening to inquire about a range of difficulties that commonly occur among individuals with advanced cancer. There are questions that address various physical symptoms, social concerns, psychological problems and sources of existential distress. At a more global level, individual items were included that inquired about the respondent's overall level of 'suffering' (12), as well as an assessment of the desire for death (14).

As with semistructured interviews that are used frequently in psychiatric research, such as the Schedule for Affective Disorders and Schizophrenia (15), each of the 22 problems reviewed with the SISC begins with a structured lead question to identify whether the problem is present for the respondent. If so, the introductory inquiry is followed by a series of additional prompts to clarify how severely the respondent is bothered by it. The interviewer then rates the severity on a seven-point ordinal scale $(0=$ no problem to $6=$ extreme). Each of the scale points has reference anchors to ensure that ratings are performed consistently by different interviewers. For each item, a rating of 3 or greater indicates that the participant has explicitly acknowledged that the issue represents a significant ongoing problem. In previous research, this level has been used as a cut-off score to identify people who are significantly bothered by an issue from those who are not $(12,14,16)$.

To assess the presence and severity of pain, the introductory lead question asked simply, 'Do you have any pain?' If the respondent answered affirmatively, follow-up prompts included 'How bad does it get? Does it interfere with activities you would like to do? Is it a problem for you? Does it come and go, or do you feel that way all the time? How much does it bother you? Does medication help?' Based on this information, the interviewer rated the overall severity of the participant's pain experience. In previous validation research (13), the SISC pain ratings were correlated at $\mathrm{r}=0.88, \mathrm{P}<0.001$, with visual analogue scale scores recorded by the patients themselves. They also had moderate test-retest reliability, $\mathrm{r}=0.54, \mathrm{P}<0.001$, comparable with those of visual analogue scale measures.

The SISC also included individual items assessing anxiety, depressed mood, loss of interest or pleasure in activities, and hopelessness. These items were used to assess the core criterion symptoms of specific anxiety and depressive disorders. The core items were supplemented with additional probes into the remaining symptoms required for the diagnosis of these disorders, with items drawn from the clinician evaluation guide of the Primary Care Evaluation of Mental Disorders (17). These items elicited a yes or no response as to the presence of particular symptoms required for the diagnoses in question, as defined by the Diagnostic and Statistical Manual of Mental Disorders, 4th Edition (18).

At the conclusion of the interview, the interviewer either reviewed with the participant the list of medications that had been prescribed, or took the information directly from the participant's medical record. Finally, the interviewer rated the participant on the Palliative Performance Scale (PPS; 19). The PPS is an extension of the widely used Karnofsky Performance Status Scale (20), which was modified for palliative care to include such functional concerns as ambulation, task performance, selfcare, nutritional intake and level of consciousness. The ratings were made on a scale of 0 (death) to 100 (unimpaired performance status).

\section{Data analyses}

Responses to most SISC interview items yield skewed data on ordinal scales, suggesting that nonparametric statistical procedures are the preferred method of analysis. First, the overall prevalence of pain at the different levels of severity recorded in 
TABLE 1

Prevalence of pain in the Canadian National Palliative Care Survey $(n=381)$

\begin{tabular}{|c|c|c|c|}
\hline Pain score & Definition & $\mathbf{n}$ & $\%$ \\
\hline 0 & No pain & 113 & 29.7 \\
\hline 1 & $\begin{array}{l}\text { Minimal - eg, occasional but infrequent experience of pain-related discomfort or background pain at a very low level; does } \\
\text { not interfere with activities; not regarded as a particular problem }\end{array}$ & 62 & 16.3 \\
\hline 2 & $\begin{array}{l}\text { Mild - eg, sometimes experiences a low level of pain-related discomfort; may on occasion interfere with some activities; } \\
\text { generally controlled with medication; occasionally regarded as a minor problem }\end{array}$ & 77 & 20.2 \\
\hline 3 & $\begin{array}{l}\text { Moderate - eg, definite periods of pain-related discomfort; interferes with some activities; helped but not always completely } \\
\text { controlled with medication; regarded as a significant problem }\end{array}$ & 71 & 18.6 \\
\hline 4 & $\begin{array}{l}\text { Strong - eg, regularly experiences pain-related discomfort, sometimes quite severely; interferes with many activities; helped } \\
\text { but not well controlled with medication; regarded as a prominent and ongoing problem }\end{array}$ & 38 & 10.0 \\
\hline 5 & $\begin{array}{l}\text { Severe - eg, pain is almost always present and often severe; interferes with almost all activities; medication provides little } \\
\text { relief; regarded as a troubling, serious ongoing problem }\end{array}$ & 13 & 3.4 \\
\hline 6 & $\begin{array}{l}\text { Extreme - eg, pain is constant and severe; interferes with all activities; medication provides minimal relief; regarded as a } \\
\text { pervasive, consuming and constant problem }\end{array}$ & 7 & 1.8 \\
\hline
\end{tabular}

The introductory lead question was asked of all participants; questions in parentheses were used as follow-up probes to clarify the severity of pain, as follows: Do you have any pain? (How bad does it get?) (Does it interfere with activities you would like to do?) (Is it a problem for you?) (Does it come and go, or do you feel that way all the time?) (How much does it bother you?) (Does medication help?)

the interviews was examined. Next, the survey cohort was divided into two groups based on SISC pain ratings of 3 or greater (the level at which the participant acknowledges a significant problem) or less than 3 (no pain, or pain at only a minimal or mild level that is not considered problematic by the participant). The two groups were then compared on various clinical and demographic measures, using $t$ tests for continuous variables and $\chi^{2}$ or Fisher's exact tests for categorical ones. The ratings were also dichotomozed for the other symptoms and concerns addressed by the SISC, again at the cut-off score of 3 or greater, and the differential prevalence of various problems was examined between participants with no, minimal or mild pain, and those with moderate to extreme pain.

Finally, the overall associations between the SISC pain ratings and ratings on the remaining 21 symptoms and concerns were also examined, using Spearman's rho correlations.

\section{Prevalence of pain}

\section{RESULTS}

As shown in Table 1, pain of any severity was reported by $70.3 \%$ of respondents. For $36.5 \%$, however, the pain experience was reported to be minimal or mild. A total of 129 participants (33.9\%) reported pain that was at least moderate in severity (the threshold at which pain was considered to be a significant ongoing problem). This included 20 individuals (5.2\%) for whom pain was rated as severe $(n=13)$ or extreme $(n=7)$.

Demographic and clinical characteristics of patients with low versus high levels of pain

The major demographic and clinical characteristics of participants with either no, minimal or mild pain versus those with moderate to extreme pain are presented in Table 2. Although there was no difference in the sex distribution between groups, those with higher pain levels were significantly younger than those with lower levels $(t=4.22, \mathrm{P}<0.001)$. However, their median survival duration until death (43.0 days) was less than that of patients with lower levels of pain (71.0 days; $\chi^{2}=5.85$, $\mathrm{P}=0.016)$. Functionally, they had lower scores on the PPS $(t=3.06, \mathrm{P}=0.002)$.

The participants with moderate to extreme pain were somewhat more likely to be recruited from palliative care inpatient
TABLE 2

Demographic and clinical characteristics of participants reporting low or high levels of pain

\begin{tabular}{|c|c|c|c|}
\hline Characteristic & $\begin{array}{l}\text { No pain to mild } \\
\text { pain }(n=252)\end{array}$ & $\begin{array}{l}\text { Moderate to } \\
\text { extreme pain } \\
(n=129)\end{array}$ & $\mathbf{P}$ \\
\hline Age, years, mean \pm SD & $69.1 \pm 12.7$ & $63.4 \pm 12.4$ & $<0.001$ \\
\hline \multicolumn{4}{|l|}{ Sex, n (\%) } \\
\hline Men & $105(41.7)$ & $64(49.6)$ & 0.171 \\
\hline Women & $147(58.3)$ & $65(50.4)$ & \\
\hline \multicolumn{4}{|l|}{ Medications, n (\%)* } \\
\hline Opioids & $176(70.1)$ & $118(91.5)$ & $<0.001$ \\
\hline Steroids & $104(41.4)$ & $61(47.3)$ & 0.327 \\
\hline Benzodiazepines & $107(42.6)$ & $68(52.7)$ & 0.079 \\
\hline Antidepressants & $53(21.1)$ & $33(25.6)$ & 0.392 \\
\hline Neuroleptics & $42(16.7)$ & $27(20.9)$ & 0.328 \\
\hline \multicolumn{4}{|l|}{ Setting, n (\%) } \\
\hline Palliative care unit & $122(48.4)$ & $75(58.1)$ & 0.091 \\
\hline Other setting & $130(51.6)$ & $54(41.9)$ & \\
\hline \multicolumn{4}{|l|}{ Education, n (\%) } \\
\hline High school or less & $152(60.3)$ & $63(48.8)$ & 0.110 \\
\hline More than high school & $100(39.7)$ & $66(51.2)$ & \\
\hline $\begin{array}{l}\text { Palliative Performance Scale, } \\
\text { mean } \pm \mathrm{SD}^{\dagger}\end{array}$ & $56.0 \pm 14.3$ & $51.5 \pm 12.1$ & 0.002 \\
\hline \multicolumn{4}{|l|}{ Mental disorders, n (\%) } \\
\hline Major depression & $25(9.9)$ & $25(19.4)$ & 0.015 \\
\hline Anxiety disorder & $22(8.7)$ & $31(24.0)$ & $<0.001$ \\
\hline Any disorder & $47(18.7)$ & $46(35.7)$ & $<0.001$ \\
\hline Survival duration, median (IQR) & $71.0(123.3)$ & $43.0(85.5)$ & 0.016 \\
\hline
\end{tabular}

${ }^{*}$ Two participants with missing data; ${ }^{\dagger}$ One participant with missing data. IQR Interquartile range

units than from home care or general hospital consultation services $\left(\chi^{2}=2.86, \mathrm{P}=0.091\right)$. With respect to medication management, over $90 \%$ of the group with moderate to extreme pain was being treated with opioid medications, compared with approximately $70 \%$ of those with lower levels of pain $\left(\chi^{2}=20.99\right.$, $\mathrm{P}<0.001)$. There was also a trend $\left(\chi^{2}=3.09, \mathrm{P}=0.079\right)$ for the group with moderate to extreme pain to have been prescribed benzodiazepine medications, but not antidepressants or neuroleptics. 
TABLE 3

Comparisons of participants with low or high levels of pain on other symptoms and concerns

\begin{tabular}{|c|c|c|c|}
\hline Symptom or concern & $\begin{array}{l}\text { No pain to mild } \\
\text { pain }(n=252)\end{array}$ & $\begin{array}{l}\text { Moderate to } \\
\text { extreme pain } \\
\quad(n=129)\end{array}$ & $\mathrm{P}^{*}$ \\
\hline \multicolumn{4}{|l|}{ Physical problems } \\
\hline General malaise & $71(28.2)$ & $91(70.5)$ & $<0.001$ \\
\hline Drowsiness & $62(24.6)$ & $61(47.3)$ & $<0.001$ \\
\hline Nausea & $26(10.3)$ & $39(30.2)$ & $<0.001$ \\
\hline Weakness & $124(49.2)$ & $101(78.3)$ & $<0.001$ \\
\hline Breathlessness & $57(22.6)$ & $42(32.6)$ & 0.048 \\
\hline \multicolumn{4}{|l|}{ Social-relational concerns } \\
\hline Social isolation & $20(7.9)$ & $25(19.4)$ & 0.002 \\
\hline Communication problem & $3(1.2)$ & $5(3.9)$ & 0.126 \\
\hline Burden to others & $59(23.4)$ & $39(30.2)$ & 0.173 \\
\hline Financial problem ${ }^{\dagger}$ & $19(7.6)$ & $15(11.6)$ & 0.190 \\
\hline \multicolumn{4}{|l|}{ Psychological difficulties } \\
\hline Anxiety & $26(10.3)$ & $33(25.6)$ & $<0.001$ \\
\hline Depression & $26(10.3)$ & $27(20.9)$ & 0.007 \\
\hline Loss of interest/pleasure $^{\dagger}$ & $34(13.5)$ & $20(15.5)$ & 0.243 \\
\hline Hopelessness ${ }^{\ddagger}$ & $24(9.5)$ & $18(14.2)$ & 0.224 \\
\hline \multicolumn{4}{|l|}{ Existential issues } \\
\hline Loss of resilience & $19(7.5)$ & $16(12.4)$ & 0.132 \\
\hline Loss of dignity & $12(4.8)$ & $14(10.9)$ & 0.032 \\
\hline Loss of control & $12(4.8)$ & $14(10.9)$ & 0.032 \\
\hline Spiritual crisis ${ }^{\ddagger}$ & $6(2.4)$ & $5(3.9)$ & 0.518 \\
\hline Difficulty accepting & $20(7.9)$ & $13(10.0)$ & 0.564 \\
\hline Dissatisfaction with life & $12(4.8)$ & $8(6.2)$ & 0.629 \\
\hline \multicolumn{4}{|l|}{ Global considerations } \\
\hline Suffering & 39 (15.5) & $59(45.7)$ & $<0.001$ \\
\hline Desire for death & $26(10.4)$ & $20(15.7)$ & 0.138 \\
\hline
\end{tabular}

Table entries are presented as $n$ (\%) of participants who reported specific symptoms and concerns at a moderate to extreme level. *P values are based on Fisher's exact tests; ' ${ }^{\dagger}$ one patient with missing data; ${ }^{\ddagger}$ Two patients with missing data

There was a clear association between pain severity and the prevalence of mental disorders as diagnosed with the Primary Care Evaluation of Mental Disorders. Participants with moderate to extreme pain were approximately twice as likely to meet Diagnostic and Statistical Manual of Mental Disorders, 4th Edition diagnostic criteria for major depression $\left(\chi^{2}=5.89, \mathrm{P}=0.015\right)$ and almost three times as likely to meet criteria for an anxiety disorder $\left(\chi^{2}=15.43, \mathrm{P}<0.001\right)$. Overall, the rates of any diagnosed depressive (major depression, major depression in partial remission, minor depression or dysthymia) or anxiety disorder were approximately double those in the high-pain compared with the low-pain group $\left(\chi^{2}=12.47, \mathrm{P}<0.001\right)$.

Associations between pain severity and other symptoms and concerns

Table 3 shows the prevalence rates of other problematic symptoms and concerns, broken down separately for participants with low versus high levels of pain. Recall that these data have been collapsed, so that table entries refer to the proportions of participants who were rated at a level of 3 or greater on each item. Eleven of 21 comparisons showed significantly greater rates of difficulty among those with a higher level of pain, including all five of the other physical symptoms, the socialrelational concern of social isolation, the psychological symptoms of anxiety and depression, existential concerns around loss of dignity and loss of control, and the general sense of suffering.

Spearman's rho correlations were calculated on the raw score ratings; with the large sample size, 18 of 21 correlations were actually statistically significant. Most were rather low (ie, rho $<0.22$ ) in absolute terms; however, the highest correlations were with general malaise $(\mathrm{rho}=0.44)$, the overall sense of suffering $($ rho $=0.40)$, nausea $($ rho $=0.34)$, weakness $($ rho $=0.31)$, drowsiness $($ rho $=0.29)$ and anxiety $($ rho $=0.29)$.

\section{A portrait of severe pain}

The focus of a final exploratory investigation was describing the characteristics of those 20 individuals who reported that they experienced severe or extreme pain. Although this group was too small to allow reliable statistical analyses, their clinical importance warranted special consideration. Perhaps the most striking feature of the group as a whole was their relatively young mean $( \pm S D)$ age $(58.4 \pm 14.3$ years $)$. There were nine men and 11 women, suggesting no marked sex difference in the experience of severe pain. Their average score on the PPS $(46.0 \pm 11.4)$ corresponded to a level of ambulation that comprised mainly sitting or lying, but their median survival duration (64.0 days) was comparable with the NPCS sample as a whole. There were seven individuals $(35.0 \%)$ who were diagnosed with a depressive disorder and 10 (50.0\%) who were diagnosed with an anxiety disorder. Five persons $(25.0 \%)$ had been prescribed antidepressant medication, $13(65.0 \%)$ had been prescribed benzodiazepines and 18 (90.0\%) had been prescribed opioid analgesics.

\section{DISCUSSION}

Pain is not necessarily the most prevalent symptom reported by patients with advanced cancer - weakness and general malaise were endorsed by greater numbers of participants overall. However, it continues to be one of the most feared symptoms (1) and, as we have reported elsewhere, a significant cause of suffering (12). Our finding that $70.3 \%$ of the NPCS participants reported any pain is in keeping with the conclusions of recent reviews $(3,4)$. The finding that $33.9 \%$ reported pain that was moderate to extreme is also generally in keeping with previous research, although the fact that this proportion is so high suggests that, even in this global year on cancer pain (21), much has yet to be learned about the optimal treatment of pain in advanced disease. As noted earlier, it is usually reported that over $70 \%$ of cancer patients with pain can obtain good relief, and almost $90 \%$ can achieve pain control that is at least satisfactory (8-10). Although it is certainly likely that the NPCS participants were being helped considerably by their pain medication regimens, the present findings call into question whether such generally optimistic conclusions are truly warranted. This is a particular concern given that all of the respondents had access to palliative care specialists, for whom pain control is a priority, and $91.5 \%$ were already being treated with opioid medication. Nevertheless, pain was still considered to be a problem for many, and was described as severe or extreme by $5.2 \%$ of respondents.

Some of the results concerning demographic and clinical correlates of cancer pain have been noted by other investigators. For example, previous research has reported that stable pain control is more difficult to achieve among younger 
patients with cancer $(22,23)$, a pattern that we also noted. In fact, it has been reported that younger patients with cancer are 1.2 to four times more likely to report pain than older patients, and 1.5 times more likely to report pain rated higher than 7 on a 0 to 10 numeric scale $(24,25)$. The reasons for such age differences are not entirely clear, but it may involve some combination of diminished nociception with advancing age, reduced central processing or psychosocial factors $(26,27)$.

Pain in the NPCS cohort did not occur in a vacuum. In fact, there was an association between more severe pain and all other physical symptoms that were assessed, some of which may have been exacerbated by medications used to control the pain. On the other hand, the finding that those with more severe pain also had lower performance status and shorter survival durations perhaps indicates that moderate to extreme pain, as well as other symptoms, are more likely to be experienced by those with more advanced disease. Although the survey design was not longitudinal, other investigators have noted that poor performance status is an important predictor of intense pain (25).

Pain was also associated with a number of psychosocial issues and concerns, in a manner that is quite similar to observations reported by Spiegel et al (28). As in the present study, Spiegel et al examined patients with relatively high or low levels of cancer pain. They found that depressive disorders were two to four times more common in the high-pain group, which is roughly comparable with the present findings. It has been known for some time that, among patients with cancer, measures of depression tend to be correlated with measures of pain $(29,30)$; one aspect of the current research that would be useful to investigate in the future is the possibility that the association between pain and anxiety may actually be stronger than the association between pain and depression. We can speculate that the greater association between pain and the prescription of benzodiazepines, rather than antidepressants, provides further evidence of this link. The NPCS did not collect data on psychological - as opposed to pharmacological approaches to the management of pain, anxiety and depression, so we cannot comment on the extent to which these were available to the participants.

Although it may be intuitively appealing to conclude that more severe pain is a cause of depression and anxiety, the essentially correlational nature of the observation precludes

\section{REFERENCES}

1. Wilson KG, Chochinov HM, McPherson CJ, et al. Desire for euthanasia or physician-assisted suicide in palliative cancer care. Health Psychol 2007;26:314-23.

2. Strömgren AS, Sjogren P, Goldschmidt D, Petersen MA, Pedesren L, Groenvold M. Symptom priority and course of symptomatology in specialized palliative care. J Pain Symptom Manage 2006;31:199-206.

3. Teunissen SCCM, Wesker W, Kruitwagen C, de Haes HCJM, Voest EE, de Graeff A. Symptom prevalence in patients with incurable cancer: A systematic review. J Pain Symptom Manage 2007;34:94-104.

4. van den Beuken-van Everdingen MHJ, de Rijke JM, Kessels AG, Schouten HC, van Kleef M, Patijn J. Prevalence of pain in patients with cancer: A systematic review of the past 40 years. Ann Oncol 2007;18:1437-49.

5. van den Beuken-van den Everdingen M, de Rijke JM, Kessels AG, Schouten HC, van Kleef M, Patijn J. High prevalence of pain in patients with cancer in a large population-based study in The Netherlands. Pain 2007;132:312-20. our making such causal interpretations. In fact, Spiegel and Bloom (31) offered a bidirectional explanation for the paindepression link. On the one hand, people with more intense pain may be at risk for becoming depressed. On the other hand, depression and anxiety may result in an amplification of the pain experience, or at least a difficulty in tolerating the stress of physical symptoms (31). As we have noted elsewhere (11), the combination of pain, depression and anxiety begins to approximate the clinical concept of 'total pain' (32). Moreover, psychological distress is included as a core dimension of the Edmonton Classification System for Cancer Pain (33), and is related to an increased amount of time to achieve stable pain control (34). Participants with pain and comorbid depression and anxiety disorders appear to have particularly high rates of global suffering (11).

\section{SUMMARY}

It must be concluded, perhaps with some discouragement, that pain remains a significant problem for many people who receive palliative care for cancer. It should be noted, however, that we did not actually ask participants if they were dissatisfied with their pain management, or whether they felt they were being undertreated. Other evidence suggests that many patients are prepared to endure some pain without escalating their doses of opioids, whether because of fear of addiction, dislike of mental or physical side effects, or not wanting to take more medication (35). Nevertheless, continued vigilance is required to monitor the pain experience of the terminally ill, particularly among younger, distressed individuals who are approaching death.

ACKNOWLEDGEMENTS: The Canadian National Palliative Care Survey was supported by a grant (reference number 42538) from the Canadian Institutes of Health Research (CIHR). HM Chochinov is a Tier 1 Canada Research Chair of the CIHR. PR Gagnon is a Research Scientist of the National Cancer Institute of Canada with funds from the Canadian Cancer Society and the CIHR. RL Fainsinger is supported by the CIHR through a grant for the New Emerging Team in Difficult Pain Problems and an international multicentre validation study of a pain classification system for advanced cancer patients. This work was presented at the 12 th World Congress on Pain, Glasgow, Scotland, United Kingdom, August 2008.
6. World Health Organization. Cancer Pain Relief, 2nd edn. With a guide to opioid availability. Geneva: World Health Organization, 1996.

7. Marinangeli F, Cicozzi A, Leonardis $\mathrm{M}$, et al. Use of strong opioids in advanced cancer pain: A randomized trial. J Pain Symptom Manage 2004:27:409-16.

8. Meuser T, Pietruck C, Radbruch L, Stute P, Lehmann KA, Grond S. Symptoms during cancer pain treatment following WHOguidelines: A longitudinal follow-up study of symptom prevalence, severity and etiology. Pain 2001;93:247-57.

9. Zech DFJ, Grond S, Lynch J, Hertel D, Lehmann KA. Validation of World Health Organization Guidelines for cancer pain relief: A 10-year prospective study. Pain 1995;63:65-76.

10. Ventafridda V, Tamburini M, Caraceni A, De Conno F, Naldi F. Study of the WHO method for cancer pain relief. Cancer 1987;59:850-6.

11. Wilson KG, Chochinov HM, Skirko MG, et al. Depression and anxiety disorders in palliative cancer care. J Pain Symptom Manage 2007;33:118-29. 
12. Wilson KG, Chochinov HM, McPherson CJ, et al. Suffering with advanced cancer. J Clin Oncol 2007;25:1691-7.

13. Wilson KG, Graham ID, Viola RA, et al. Structured interview assessment of symptoms and concerns in palliative care. Can J Psychiatry 2004:49:350-8.

14. Chochinov HM, Wilson KG, Enns M, et al. Desire for death in the terminally ill. Am J Psychiatry 1995;152:1185-91.

15. Endicott J, Spitzer RL. A diagnostic interview: The Schedule for Affective Disorders and Schizophrenia. Arch Gen Psychiatry 1978;35:837-44.

16. Wilson KG, Curran D, McPherson CJ. A burden to others: A common source of distress for the terminally ill. Cogn Behav Ther 2005;34:115-23.

17. Spitzer RL, Williams JBW, Kroenke K, et al. Utility of a new procedure for diagnosing mental disorders in primary care: The PRIME-MD 1000 study. JAMA 1994:272:1749-56.

18. American Psychiatric Association. Diagnostic and Statistical Manual of Mental Disorders, 4th edn. Washington: American Psychiatric Association, 1994.

19. Anderson F, Downing GM, Hill J. Palliative Performance Scale (PPS): A new tool. J Palliat Care 1996;12:5-11.

20. Mor V, Laliberte L, Morris JN, Wiemann M. The Karnofsky Performance Status Scale: An examination of its reliability and validity in a research setting. Cancer 1984;53:2002-7.

21. Kalso E, Paice J. Global year on cancer pain. Pain 2008;140:247-8.

22. Fainsinger RL, Nekolaichuk CL, Lawlor PG, et al. A multicenter study of the revised Edmonton Staging System for classifying cancer pain in advanced cancer patients. J Pain Symptom Manage 2005;29:224-37.

23. Nekolaichuk CL, Fainsinger RL, Lawlor PG. A validation study of a pain classification system for advanced cancer patients using content experts: The Edmonton Classification System for cancer pain. Palliat Med 2005;19:466-76.
24. Pickering G. Age differences in clinical pain states. In: Gibson SJ, Weiner DK, eds. Pain in Older Persons. Seattle: IASP Press, 2005:67-85.

25. Caraceni A, Portenoy RK. An international survey of cancer pain characteristics and syndromes. IASP Task Force on Cancer Pain. International Association for the Study of Pain. Pain 1999;82:263-74.

26. Edwards RR. Age-associated differences in pain perception and pain processing. In: Gibson SJ, Weiner DK, eds. Pain in Older Persons. Seattle: IASP Press, 2005:45-65.

27. Gibson SJ, Farrell M. A review of age differences in the neurophysiology of nociception and the perceptual experience of pain. Clin J Pain 2004;20:227-39.

28. Spiegel D, Sands S, Koopman C. Pain and depression in patients with cancer. Cancer 1994;74:2570-8.

29. Wilson KG, Lander M, Chochinov HM. Diagnosis and management of depression in palliative care. In: Chochinov HM, Breitbart W, eds. Handbook of Psychiatry in Palliative Medicine, 2nd edn. New York: Oxford University Press, 2009:39-68.

30. Laird BJA, Boyd AC, Colvin LA, Fallon MT. Are cancer pain and depression interdependent? A systematic review. Psychooncology 2009;18:459-64.

31. Spiegel D, Bloom JR. Pain in metastatic breast cancer. Cancer $1983 ; 52: 341-5$

32. Saunders C. The evolution of palliative care. Patient Educ Couns 2000;41:7-13.

33. Fainsinger RL, Nekolaichuk CL. A "TNM" classification system for cancer pain: The Edmonton Classification System for Cancer Pain (ECS-CP). Support Care Cancer 2008;16:547-55.

34. Fainsinger RL, Fairchild A, Nekolaichuk C, Lawlor P, Lowe S, Hanson J. Is pain intensity a predictor of the complexity of cancer pain management? J Clin Oncol 2009;27:585-90.

35. Weiss SC, Emanuel LL, Farrclough DL, Emanuel EJ. Understanding the experience of pain in terminally ill patients. Lancet 2001;357:1311-5. 


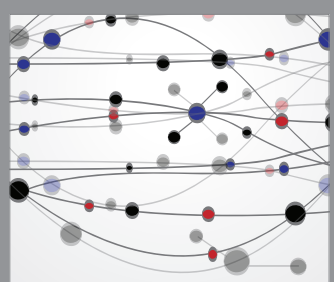

The Scientific World Journal
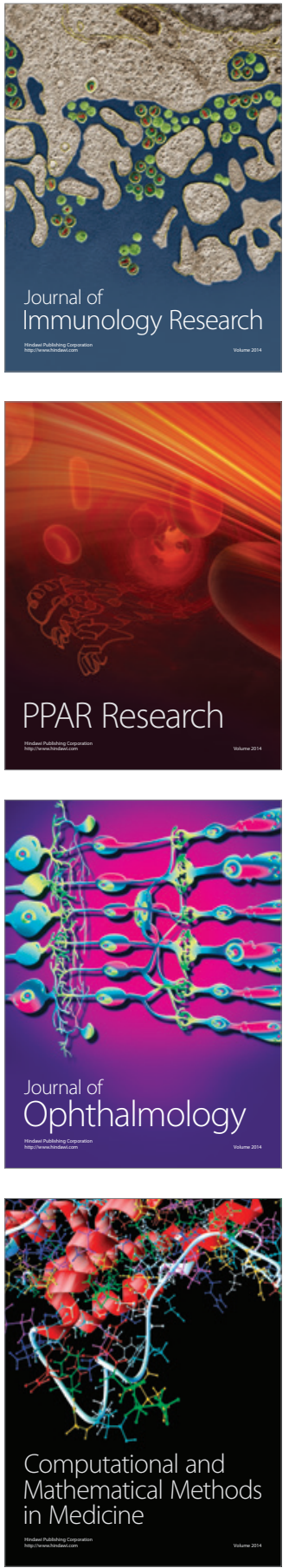

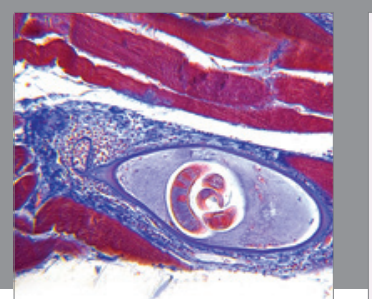

Gastroenterology Research and Practice

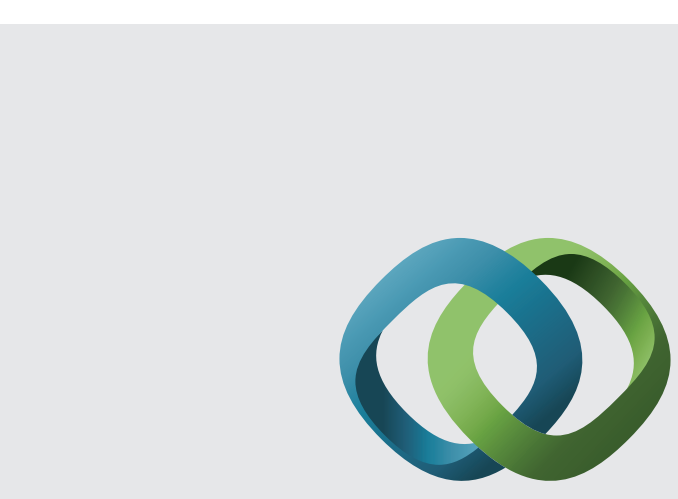

\section{Hindawi}

Submit your manuscripts at

http://www.hindawi.com
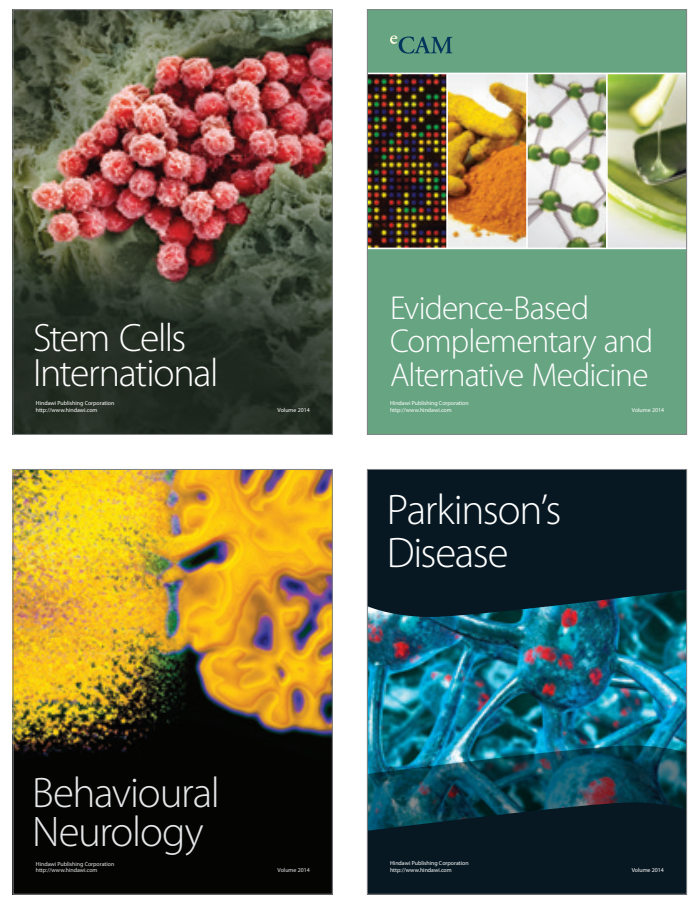
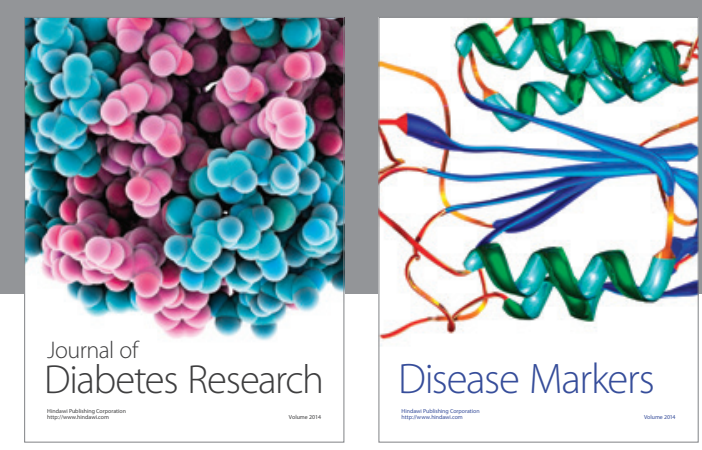

Disease Markers
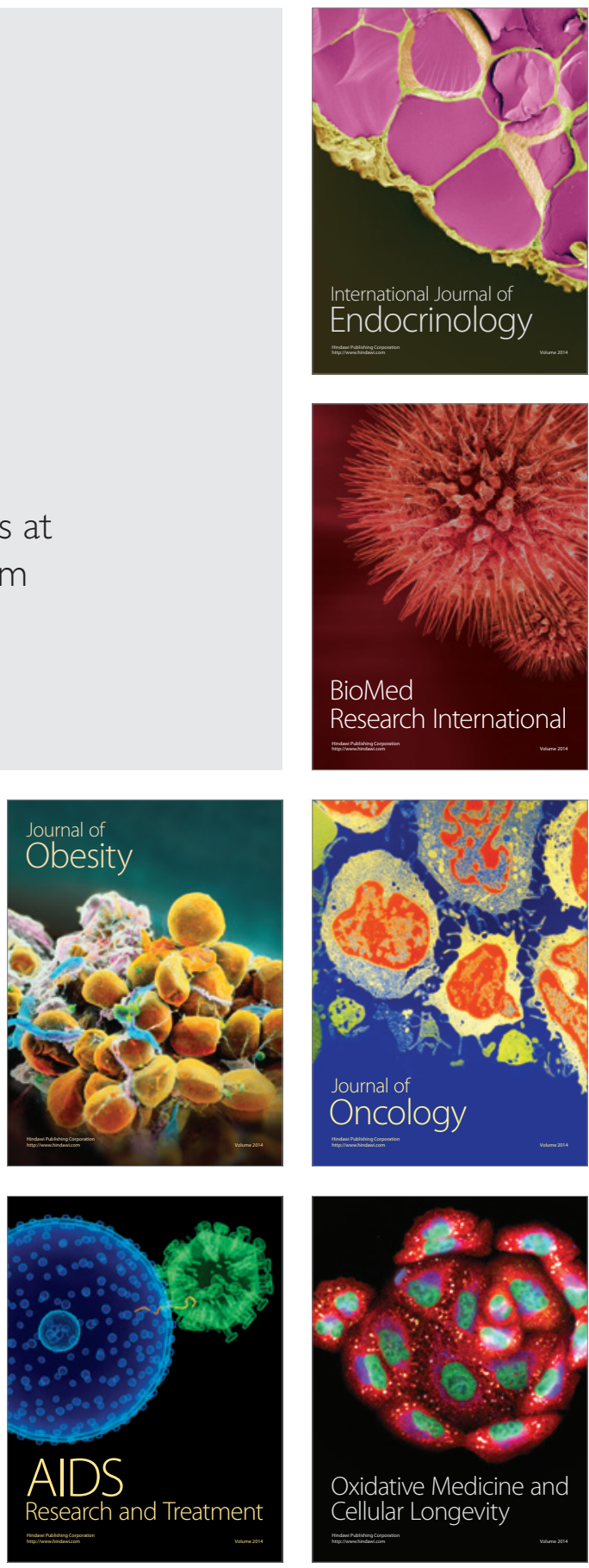